\title{
OPEN Experimental investigation of oil-water flow in the horizontal and vertical sections of a continuous transportation pipe
}

\begin{abstract}
Jianlei Yang ${ }^{1}$, Peng $\mathrm{Li}^{2}$, Xuhui Zhang ${ }^{2,3}$, Xiaobing Lư ${ }^{2,3}$, Qing $\mathrm{Li}^{4}$ \& Lifei Mi ${ }^{5}$
A series of experiments were conducted to investigate flow pattern transitions and concentration distribution during simultaneous pipe flow of oil-water two-phase flow through the horizontal and vertical sections. The flowing media applied were white mineral oil and distilled water. Superficial oil and water velocities were between 0 and $0.57 \mathrm{~m} / \mathrm{s}$. Flow pattern maps revealed that the horizontal and vertical sections of the pipe lead to different flow pattern characteristics under the same flow conditions. The original contributions of this work are that a transition mechanism for predicting the boundary between oil-in-water (O/W) flow and water-in-oil (W/O) in oil-water two-phase flow was obtained. The effects of input water cut, oil and water superficial velocities on the concentration distribution of the dispersed phase were studied. The empirical formulas for the phase holdup based on the drift-flux model were obtained. The predicted results agreed well with those of the experimental data, especially for the O/W flow pattern.
\end{abstract}

With the increase of oil well production life, the volume fraction of water in oil pipes may gradually increase ${ }^{1}$. The oil-water two-phase flow in the pipe is a crucial topic in the petroleum industry. The oil-water flow is characterized by a variety of diverse flow patterns. Different concentration and pressure drop distribution characteristics occurred under different flow patterns. The understanding of flow pattern and phase holdup is of great importance for the evaluation of oilfield operating and oil production. The change of the flow pattern has a vital impact on the pressure drop, spatial phase distribution, and safety of pipeline transportation ${ }^{2}$. The calculation of water holdup is helpful to predict the oil transportation in oil pipelines, and water holdup is an important parameter in identifying flow patterns ${ }^{3}$.

Many researchers have been studied the simultaneous oil and water flow in horizontal or vertical pipes. For horizontal oil-water flows, the flow patterns are mainly divided into the segregated flow and the dispersed flow. The segregated flow did not occur in pipes with an inclination of more than 33 . The oil-water flow often occurs as the dispersed flow ${ }^{4}$. Piela et al. ${ }^{5}$ studied the phase inversion of oil-water flow experimentally through a horizontal pipe loop. The experiments were carried in a pipe loop with an inner pipe diameter of $16 \mathrm{~mm}$, consisting of two straight parts of $6 \mathrm{~m}$ connected via two bends. Experimental data showed that the phase inversion occurred at the oil volume fraction of 0.9 for the water-to-oil inversion, and the pressure drop increases at the inversion compared to the initial pressure drop. The volume fraction of the dispersed phase at the water-to-oil experiment transition point was higher than that for oil-to-water experiments. Gong et al. ${ }^{6}$ developed a model for predicting phase inversion in oil-water flow in a stainless steel pipe loop using the relations between the surface energies before and after phase inversion. The results of the model were in reasonable agreement with the experimental results. The experiments were conducted in a stainless steel pipe loop ( $25.7 \mathrm{~mm}$ inner diameter, $52 \mathrm{~m}$ long). The experimental temperature was $40{ }^{\circ} \mathrm{C}, 50^{\circ} \mathrm{C}$, and $60{ }^{\circ} \mathrm{C}$, respectively. Kumara et al. measured an oil-water twophase flow in a horizontal pipe with a diameter of $56 \mathrm{~mm}$ and length of $15 \mathrm{~m}$ with particle image velocimetry and laser Doppler anemometry ${ }^{7}$. Zhou et al. designed parallel-wire conductivity probes to measure water hold-up of oil-water two-phase flow in a near-horizontal pipe. The experimental data showed that the method can achieve a good measurement result of water hold-up ${ }^{8}$. Wang et al. conducted oil-water experiments in a small horizontal channel with $2 \mathrm{~mm}$. Flow patterns and the plug shape/length taken by highspeed camera were investigated ${ }^{9}$.

\footnotetext{
${ }^{1}$ Hebei Petroleum University of Technology, Chengde 067000, China. ${ }^{2}$ Institute of Mechanics, Chinese Academy of Sciences, Beijing 100190, China. ${ }^{3}$ School of Engineering Science, University of Chinese Academy of Sciences, Beijing 100049, China. ${ }^{4}$ Engineering and Construction Department, Dagang Oilfield, Tianjin 300280, China. ${ }^{5}$ Oil Production Technology Institute, Dagang Oilfield, Tianjin 300280, China. ${ }^{\circledR}$ email: lipeng@imech.ac.cn
} 
For vertical oil-water systems, Hasan and $\mathrm{Kablr}^{10}$ adopted the drift-flux model to predict in situ oil volume fraction in oil-water flow. The model parameters were determined by the experimental data. The experimental rig consisted of two separate $5.5 \mathrm{~m}$ long transparent columns with 64 and $127 \mathrm{~mm}$ inner diameters. Xu et al. ${ }^{11}$ conducted an experimental study of a co-current upward and downward in a transparent vertical pipe. The phase inversion and frictional pressure gradients were investigated using white oil and water in a $50 \mathrm{~mm}$ inner diameter pipe. The flow patterns are usually recognized by visual inspection and the fluctuations in the volume fraction. Keska et al. ${ }^{12}$ carried out the comparative experimental research on four methods (capacitive, resistive, optical, and pressure) commonly adopted to identify the flow pattern, and the results proved that the best way to judge the flow pattern is to use the capacitance or resistance fluctuation of the flow cross-section. The values of resistance and capacitance represent the change in the volume fraction. Jones and Zuber ${ }^{13}$ demonstrated that the probability density function (PDF) of the fluctuations in the volume fraction can be used as a statistical analysis tool for flow pattern identification. The PDF is a function of signal amplitude and a method of measuring the probability that a signal has a range of values. In this study, the PDF of the volume fraction of the water phase is used to identify changes in the flow pattern. Du et al. employed convolutional neural networks to identify oil-water two-phase flow patterns. The different flow pattern images were collected through oil-in-water flow experiments in a vertical $20 \mathrm{~mm}$ inner diameter Plexiglas pipe. The flow pattern images were collected by the highspeed camera ${ }^{14}$.

However, few comparative studies of horizontal and vertical flows in a combined pipe have been reported. In the on-site oil pipeline layout, the pipeline is horizontal, vertical, or even inclined. Under the same flow parameters, pipelines in different directions may show different flow pattern characteristics, which brings hidden dangers to the stability of pipeline transportation. Under the same flow parameters, it is necessary to study the different flow behaviors in horizontal and vertical pipelines ${ }^{3}$.

The oil-water flow in the pipe is complex and related to pipe geometries (e.g., inner pipe diameter, pipe angle), fluid properties (e.g., viscosity, density, and surface tension), and boundary conditions (e.g., superficial input velocities). Previous studies mainly focused on the effect of a single parameter, but the coupled effect of the controlling parameters on the flow is not well understood. Hence, to understand the fundamental mechanisms of oil-water flows, the controlling dimensionless parameters were derived by dimensional analysis first.

Thus, the objective of this work was to investigate the flow pattern transition and phase holdup for an oil-water two-phase flow through the horizontal and vertical sections, a comparative study of the flow behavior has been conducted in a pipe loop by using different superficial input velocities. A series of experiments were conducted to investigate the oil-water flow pattern transition and the water holdup, considering both the horizontal and vertical sections of a transportation pipe.

The current paper is structured as follows. The experimental setup is described in "Experimental setup and procedure" section. The dimensional analysis is presented in "Dimensional analysis and data structure" section. The overall results in terms of flow pattern and phase holdup are discussed in "Results and discussion" section. The relationship between the transient water holdup and the change of the flow pattern in a transportation pipe with horizontal and vertical sections is established, and the empirical formulas for the phase holdup based on the drift-flux model are obtained. Finally, "Conclusion" section presents the conclusions of this study.

\section{Experimental setup and procedure}

Experimental facility. The experimental study for oil-water flow was conducted in a closed circuit loop. The schematic drawing of the flow loop is depicted in Fig. 1, which can be used to carry out both oil-water or oil-water-gas flow experiments. The test equipment can identify the oil-water flow patterns and record the water holdup (in situ volume fraction of water) and the pressure drop.

The flowing pipe was composed of a stainless steel pipe section and a plexiglass pipe section, and its inner diameter was $50 \mathrm{~mm}$. The flow pattern development section was a horizontal stainless steel pipe with a length of $10 \mathrm{~m}$ from the entrance (corresponding to $200 \mathrm{D}$, where $D$ was the inner diameter). Based on the experimental observation, this length ensured that a fully developed flow can be achieved before measurement ${ }^{6}$. Due to the mixture velocities were low $(u<0.57 \mathrm{~m} / \mathrm{s})$ and oil phase viscosity high $(32 \mathrm{mPa} \mathrm{s})$, this length provided sufficient length to stabilize the flow. Flores ${ }^{2}$ also used the development length of about 200 diameters to study the characterization of oil-water flow patterns. The reasonableness of the development length is further confirmed in "Flow pattern maps" section.

The flow observation sections consisted of a $1 \mathrm{~m}$ long horizontal transparent pipe and a $2 \mathrm{~m}$ long vertical transparent pipe. With this arrangement, experiments on horizontal and vertical flows can be carried out simultaneously. The water was pumped first by a centrifugal pump (QABP160M2A, ABB), with a capacity of $12.5 \mathrm{~m}^{3} / \mathrm{h}$. Then the oil phase was pumped into the clapboard mixer in which the oil was mixed with the water. A $6.99 \mathrm{KW}$ gear pump (SNH440) with a capacity of $17 \mathrm{~m}^{3} / \mathrm{h}$ and accuracy of $\pm 0.1 \%$ of the reading was used for the oil phase. The oil and water phases entered the double-Y junction fitting mixer from the upper and lower layers of the mixer, respectively. The angle of the meeting point of the oil and water flow lines before entering the mixer is 60 degrees. The oil-water mixture flowed simultaneously to the test section and then flowed down the return section to the separating tank. Leaving the separating tank, the oil and water were directed to their original tanks. The liquid volume flow rate was monitored by a mass flowmeter (CMF100, Micro Motion), whose accuracy was $\pm 0.1 \%$.

Measuring equipment. Measurements included water holdup, pressure drop, and flow patterns, in addition to recording parameters such as the volume flow rate of each phase and the experimental temperatures. A differential pressure transducer was installed in the return section to measure the pressure drop at a frequency of $1 \mathrm{~Hz}$. When the pressure drop was independent of time, it was deemed that a steady state of the system was reached. Then a total of $300 \mathrm{~s}$ of data was recorded. A digital video was used to observe the flow structures and 


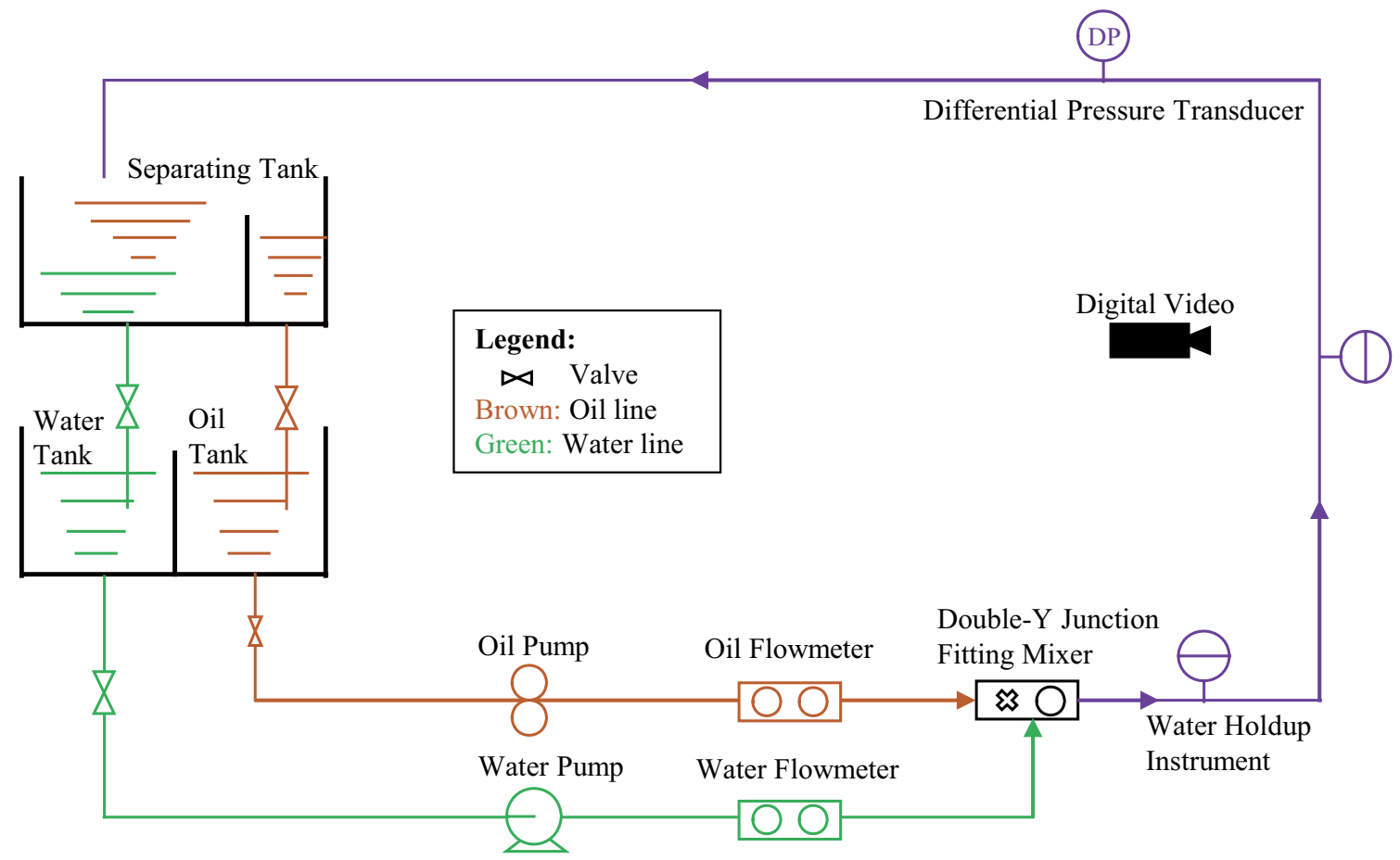

Figure 1. Schematic drawing of the flow loop used in this study.

\begin{tabular}{|l|l|l|l|}
\hline & Density, $\boldsymbol{\rho}\left(\mathbf{k g} / \mathbf{m}^{3}\right)$ & Viscosity, $\boldsymbol{\mu}(\mathbf{m P a} \mathbf{s})$ & Interfacial tensions, $\boldsymbol{\sigma}(\mathbf{m N} \mathbf{~ m})$ \\
\hline White mineral oil & 843 & 32 & - \\
\hline Distilled water & 998.2 & 1 & Water/oil, 42 \\
\hline
\end{tabular}

Table 1. Properties of water and oil phases measured at atmospheric pressure and $20^{\circ} \mathrm{C}$.

identify the flow patterns. The working fluids used in the experiments were white mineral oil and distilled water. All experiments were carried out under atmospheric pressure, and the room temperature was controlled at about $20^{\circ} \mathrm{C}$. The physical parameters of the oil phase and water phase are shown in Table 1.

Two water holdup instruments equipped with a conductance probe were assembled in the horizontal and vertical sections of the test pipe to measure the cross-sectional average water holdup $\alpha_{\mathrm{w}}$ at a sampling frequency of $1 \mathrm{~Hz}$, respectively. The photograph of the water holdup instrument is shown in Fig. $2^{3}$. The conductance probe measured the voltage between the two ends of the conductor, which allowed the mean conductivity of the mixture in the pipe to be calculated. Due to the poor conductivity of the oil phase, the voltage value measured when the pipe was filled with pure oil was much higher than that when the pipe was filled with pure water. The voltage values of pure oil and water were denoted by $V_{\mathrm{o}}$ and $V_{\mathrm{w}}$, respectively. Then, the mean conductivity $V_{\exp }$ of the in-suit liquid can be determined by the following equation:

$$
V_{\exp }=f\left(\alpha_{\mathrm{w}}, V_{\mathrm{w}}, V_{\mathrm{o}}\right)
$$

Taking $V_{\mathrm{w}}$ as a unit system produced the following dimensionless relationship:

$$
\frac{V_{\text {exp }}}{V_{\mathrm{w}}}=f\left(\alpha_{\mathrm{w}}, \frac{V_{\mathrm{o}}}{V_{\mathrm{w}}}\right)
$$

According to the mixture theory ${ }^{15}$, it was assumed that the voltage value of the mixture satisfied the following relationship:

$$
\frac{V_{\exp }}{V_{\mathrm{w}}}=\alpha_{\mathrm{w}}+\left(1-\alpha_{\mathrm{w}}\right) \frac{V_{\mathrm{o}}}{V_{\mathrm{w}}}
$$

The relationship between water holdup $\alpha_{\mathrm{w}}$ and the mean conductivity of the mixture $V_{\exp }$ can be expressed as:

$$
\alpha_{\mathrm{w}}=\frac{V_{\mathrm{o}}-V_{\mathrm{exp}}}{V_{\mathrm{o}}-V_{\mathrm{w}}}
$$




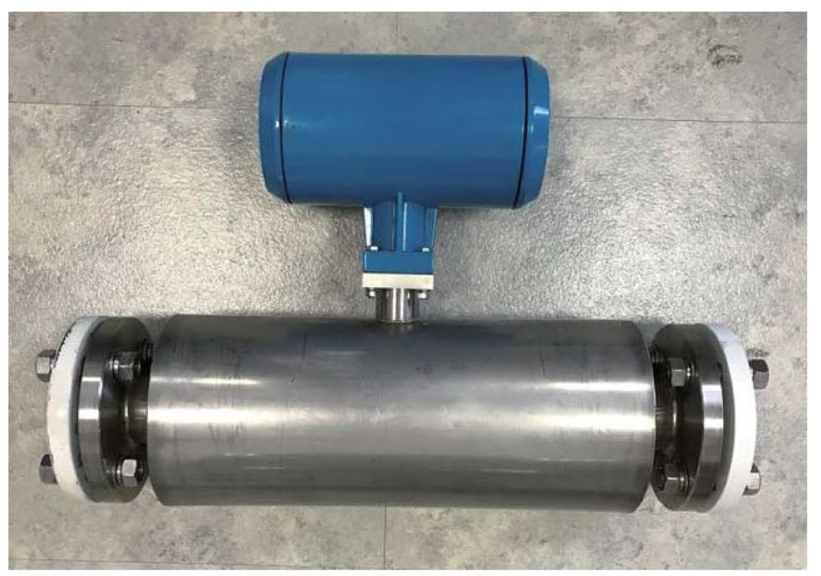

(a)

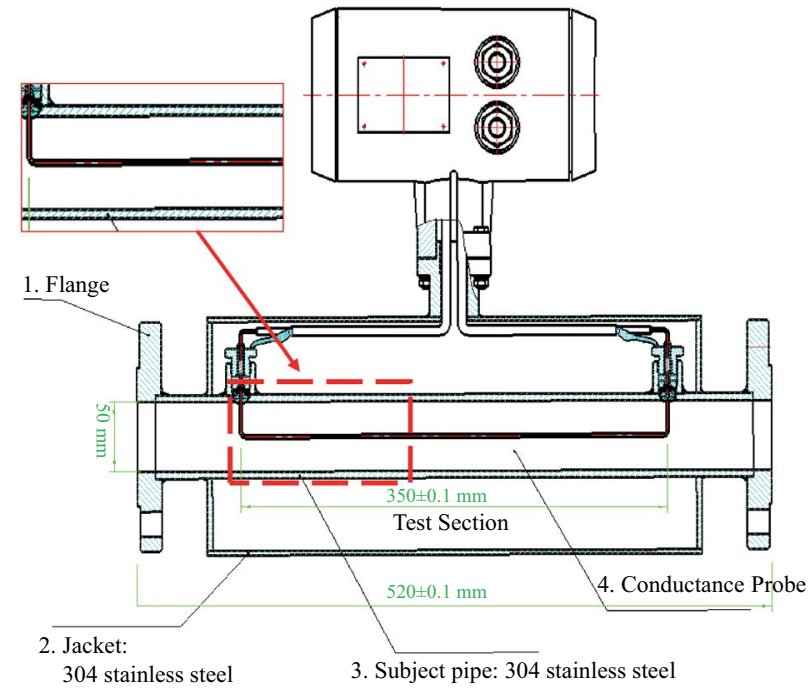

(b)

Figure 2. (a) Photograph of the water holdup instrument designed for the experiments. (b) The internal structure of the water holdup instrument ${ }^{3}$.

Noting that the voltage values of pure water and pure oil were slightly different under different experimental conditions. Therefore, both $V_{\mathrm{o}}$ and $V_{\mathrm{w}}$ adopt the values measured under the current experimental condition when the voltage value signal was converted into the water holdup using Eq. (4).

\section{Dimensional analysis and data structure}

The flow patterns of oil-water two-phase flow are classically organized into the separated flow and dispersed flow $^{4}$. The dispersed flow frequently occurs in oil-water flow, where one phase is dispersed phase, and the other is continuous phase. These two types of dispersion spontaneously invert at some operational conditions, which is called phase inversion. A single uppercase subscript $C$ refers to the continuous phase and $D$ refers to the dispersed phase. The parameters controlling the oil-water two-phase dispersed flow are listed as follows:

Dispersed phase: density $\rho_{D}$, viscosity $\mu_{D}$, drop diameter $d_{D}$, interfacial tension $\sigma$.

Continuous phase: density $\rho_{C}$, viscosity $\mu_{C}$.

Geometric parameter: inner pipe diameter $D$.

Boundary condition: superficial input velocity $u_{s}$ which is defined as $u_{s}=Q / A$ where $Q$ is the volume flow rate of each phase and $A$ is the cross-sectional area of the pipe, $A=\pi D^{2} / 4$.

Gravitational acceleration: $g$.

The eventual steady state of the oil-water flow system, characterized by the holdup of the dispersed phase $\alpha_{D}$, pressure drop $\Delta P$, and flow pattern, is a function of the above controlling parameters:

$$
\left(\alpha_{D}, \Delta P, \text { flow pattern }\right)=f\left(\rho_{C}, \mu_{C}, u_{s C} ; \rho_{D}, \mu_{D}, u_{s D}, d_{D}, \sigma ; D, g\right)
$$

Equation (5) can be nondimensionalized as:

$$
\left(\alpha_{D}, \frac{\Delta P}{\rho_{C} u_{s C}^{2}}, \text { flow pattern }\right)=f\left(\frac{u_{s D}}{u_{s C}}, \frac{\rho_{C} u_{s C} D}{\mu_{C}}, \frac{u_{s C}^{2}}{g D}, \frac{\left|\rho_{C}-\rho_{D}\right| g D^{2}}{\sigma}, \frac{\mu_{D}}{\mu_{C}}, \frac{\rho_{D}}{\rho_{C}}, \frac{d_{D}}{D}\right)
$$

where $u_{s D} / u_{s C}$ is the superficial velocity ratio, $\rho_{C} u_{s C} D / \mu_{C}$ is Reynolds number $R e_{C}, u_{s C}^{2} / g D$ is Froude number FrC. $\left(\left|\rho_{C}-\rho_{D}\right| g D^{2}\right) / \sigma$ is Eötvös number Eo that represents the ratio of buoyancy force to surface tension force. For a wholly developed dispersed flow, the velocity difference between oil and water phases is minimal. Then, in the present paper, the dimensionless numbers are calculated instead of the superficial velocity $u_{s}$, with the total superficial velocity $u_{s m}$.

$$
u_{s \mathrm{~m}}=u_{s C}+u_{s D}
$$

Defining input water cut $\varepsilon_{\mathrm{w}}$ as the ratio of the water flow rate to the mixture flow rate.

$$
\varepsilon_{\mathrm{w}}=\frac{Q_{\mathrm{w}}}{Q_{\mathrm{w}}+Q_{\mathrm{o}}}=\frac{u_{\mathrm{sw}}}{u_{s \mathrm{~m}}}
$$

Assuring that the fluid properties and drop size remain constant, i.e., Eötvös number $E$ o, density ratio $\rho_{D} / \rho_{C}$, viscosity ratio $\mu_{D} / \mu_{C}$, and the ratio of drop size to pipe diameter $d_{D} / D$ are fixed. Therefore, the Eq. (6) can be modified as: 


\begin{tabular}{|c|c|c|c|c|c|c|}
\hline Test & $Q_{w}\left(\mathrm{~m}^{3} / \mathrm{s}\right)$ & $Q_{0}\left(\mathrm{~m}^{3} / \mathrm{s}\right)$ & $u_{s w}(\mathrm{~m} / \mathrm{s})$ & $u_{s o}(\mathrm{~m} / \mathrm{s})$ & $\varepsilon_{\mathrm{w}}$ & $u_{s \mathrm{~m}}^{2} / g D$ \\
\hline 1 & 0 & $44.44 \times 10^{-5}$ & 0.00 & 0.23 & 0 & 0.108 \\
\hline 2 & $4.44 \times 10^{-5}$ & $40.00 \times 10^{-5}$ & 0.02 & 0.20 & 0.1 & 0.108 \\
\hline 3 & $8.89 \times 10^{-5}$ & $35.56 \times 10^{-5}$ & 0.05 & 0.18 & 0.2 & 0.108 \\
\hline 4 & $13.33 \times 10^{-5}$ & $31.11 \times 10^{-5}$ & 0.07 & 0.16 & 0.3 & 0.108 \\
\hline 5 & $17.78 \times 10^{-5}$ & $26.67 \times 10^{-5}$ & 0.09 & 0.14 & 0.4 & 0.108 \\
\hline 6 & $22.22 \times 10^{-5}$ & $22.22 \times 10^{-5}$ & 0.11 & 0.11 & 0.5 & 0.108 \\
\hline 7 & $26.67 \times 10^{-5}$ & $17.78 \times 10^{-5}$ & 0.14 & 0.09 & 0.6 & 0.108 \\
\hline 8 & $31.11 \times 10^{-5}$ & $13.33 \times 10^{-5}$ & 0.16 & 0.07 & 0.7 & 0.108 \\
\hline 9 & $35.56 \times 10^{-5}$ & $8.89 \times 10^{-5}$ & 0.18 & 0.05 & 0.8 & 0.108 \\
\hline 10 & $40.00 \times 10^{-5}$ & $4.44 \times 10^{-5}$ & 0.20 & 0.02 & 0.9 & 0.108 \\
\hline 11 & $44.44 \times 10^{-5}$ & 0 & 0.23 & 0.00 & 1.0 & 0.108 \\
\hline 12 & 0 & $63.89 \times 10^{-5}$ & 0.00 & 0.33 & 0 & 0.222 \\
\hline 13 & $6.39 \times 10^{-5}$ & $57.50 \times 10^{-5}$ & 0.03 & 0.29 & 0.1 & 0.222 \\
\hline 14 & $12.78 \times 10^{-5}$ & $51.11 \times 10^{-5}$ & 0.07 & 0.26 & 0.2 & 0.222 \\
\hline 15 & $19.17 \times 10^{-5}$ & $44.72 \times 10^{-5}$ & 0.10 & 0.23 & 0.3 & 0.222 \\
\hline 16 & $25.56 \times 10^{-5}$ & $38.33 \times 10^{-5}$ & 0.13 & 0.20 & 0.4 & 0.222 \\
\hline 17 & $31.94 \times 10^{-5}$ & $31.94 \times 10^{-5}$ & 0.16 & 0.16 & 0.5 & 0.222 \\
\hline 18 & $38.33 \times 10^{-5}$ & $25.56 \times 10^{-5}$ & 0.20 & 0.13 & 0.6 & 0.222 \\
\hline 19 & $44.72 \times 10^{-5}$ & $19.17 \times 10^{-5}$ & 0.23 & 0.10 & 0.7 & 0.222 \\
\hline 20 & $51.11 \times 10^{-5}$ & $12.78 \times 10^{-5}$ & 0.26 & 0.07 & 0.8 & 0.222 \\
\hline 21 & $57.50 \times 10^{-5}$ & $6.39 \times 10^{-5}$ & 0.29 & 0.03 & 0.9 & 0.222 \\
\hline 22 & $63.89 \times 10^{-5}$ & 0 & 0.33 & 0.00 & 1.0 & 0.222 \\
\hline 23 & 0 & $111.11 \times 10^{-5}$ & 0.00 & 0.57 & 0 & 0.663 \\
\hline 24 & $11.11 \times 10^{-5}$ & $100.00 \times 10^{-5}$ & 0.06 & 0.51 & 0.1 & 0.663 \\
\hline 25 & $22.22 \times 10^{-5}$ & $88.89 \times 10^{-5}$ & 0.11 & 0.45 & 0.2 & 0.663 \\
\hline 26 & $33.33 \times 10^{-5}$ & $77.78 \times 10^{-5}$ & 0.17 & 0.40 & 0.3 & 0.663 \\
\hline 27 & $44.44 \times 10^{-5}$ & $66.67 \times 10^{-5}$ & 0.23 & 0.34 & 0.4 & 0.663 \\
\hline 28 & $55.56 \times 10^{-5}$ & $55.56 \times 10^{-5}$ & 0.28 & 0.28 & 0.5 & 0.663 \\
\hline 29 & $66.67 \times 10^{-5}$ & $44.44 \times 10^{-5}$ & 0.34 & 0.23 & 0.6 & 0.663 \\
\hline 30 & $77.78 \times 10^{-5}$ & $33.33 \times 10^{-5}$ & 0.40 & 0.17 & 0.7 & 0.663 \\
\hline 31 & $88.89 \times 10^{-5}$ & $22.22 \times 10^{-5}$ & 0.45 & 0.11 & 0.8 & 0.663 \\
\hline 32 & $100.00 \times 10^{-5}$ & $11.11 \times 10^{-5}$ & 0.51 & 0.06 & 0.9 & 0.663 \\
\hline 33 & $111.11 \times 10^{-5}$ & 0 & 0.57 & 0.00 & 1.0 & 0.663 \\
\hline
\end{tabular}

Table 2. Data structure for the oil-water pipe flow experiments $\left(E o=90.53, \mu_{\mathrm{o}} / \mu_{\mathrm{w}}=32, \rho_{\mathrm{o}} / \rho_{\mathrm{w}}=0.84\right)$.

$$
\left(\alpha_{D}, \frac{\Delta P}{\rho_{C} u_{s \mathrm{~m}}^{2}}, \text { flow pattern }\right)=f\left(\varepsilon_{\mathrm{w}}, \frac{\rho_{C} u_{s \mathrm{~m}} D}{\mu_{C}}, \frac{u_{s \mathrm{~m}}^{2}}{g D}\right)
$$

The effects of the dimensionless parameters in Eq. (9) on the flow characteristics of the oil-water two-phase flow are investigated. All the experimental values of $u_{s \mathrm{w}}, u_{s o}$, and the corresponding dimensionless numbers are given in Table 2 . Noting that $R e_{\mathrm{m}}$ is not listed in this table and calculated according to which phase is continuous in the experiments. The material-related dimensionless parameters remain constant.

\section{Results and discussion}

Flow pattern maps. The experiments of wash-out type oil-water two-phase pipe flow were carried out by starting with pumping water first and then adding oil applying different flow rates. The identification of flow regimes was based on both visual observation and interpretation of transient flow signals (e.g., fluctuations of water holdup and pressure drop). Flores ${ }^{4}$ mainly identified water-dominated pattern (dispersion of oil in water, $\mathrm{O} / \mathrm{W}$ ) and oil-dominated pattern (dispersion of water in oil, W/O) for oil-water flow in vertical and horizontal pipes. The present work focused on the phase inversion between oil-in-water and water-in-oil dispersions.

Figure 3 shows examples of the flow patterns that were observed in this study in both the horizontal and vertical sections in a continuous transportation pipe. Figure $3 \mathrm{a}$ presents the $\mathrm{O} / \mathrm{W}$ pattern. Figure $3 \mathrm{~b}$ shows the $\mathrm{W} / \mathrm{O}$ pattern, where a liquid film with a certain thickness formed between the gas column and the pipe wall. Figure $3 \mathrm{c}$ shows the stratified flow. The upper layer was the continuous oil phase and the lower layer was the continuous water phase. Based on the experimental observations, the development length can achieve the fully developed flow patterns.

Figures 4 and 5 shows two examples of time series of the cross-sectional average water holdup $\alpha_{\mathrm{w}}$ and the corresponding PDF as a function of the water holdup for different experimental conditions. The PDF shows a 


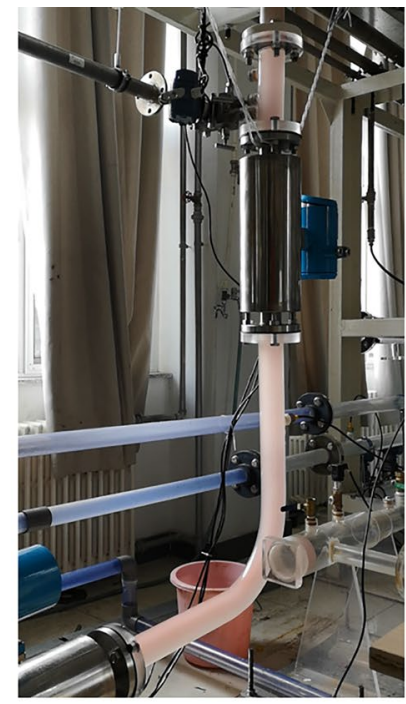

(a) Dispersion of oil in water

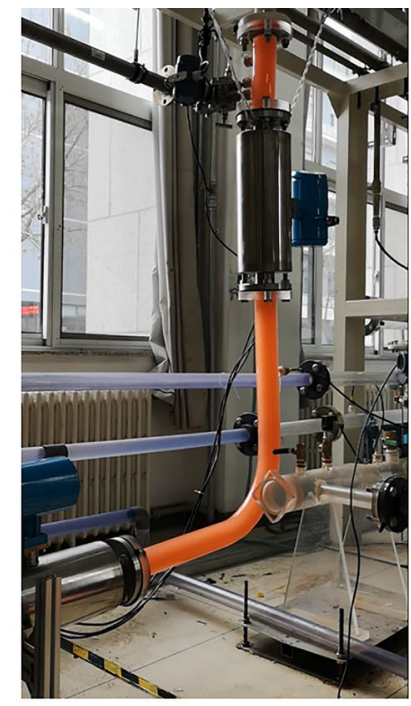

(b) Dispersion of water in oil

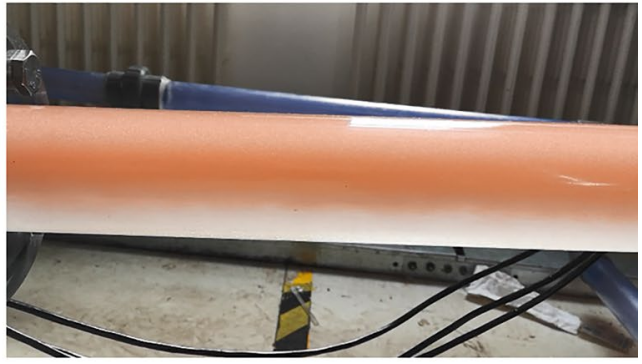

(c) Stratified flow

Figure 3. Instantaneous flow patterns observed in the experiments in the horizontal and vertical sections: (a) dispersion of oil in water, $u_{s \mathrm{w}}=0.16 \mathrm{~m} / \mathrm{s}, u_{s o}=0.07 \mathrm{~m} / \mathrm{s}$; (b) dispersion of water in oil, $u_{s \mathrm{w}}=0.02 \mathrm{~m} / \mathrm{s}$, $u_{s \mathrm{o}}=0.20 \mathrm{~m} / \mathrm{s} ;(\mathbf{c})$ stratified flow, $u_{s \mathrm{w}}=0.40 \mathrm{~m} / \mathrm{s}, u_{s \mathrm{o}}=0.17 \mathrm{~m} / \mathrm{s}$.

\section{The horizontal section}
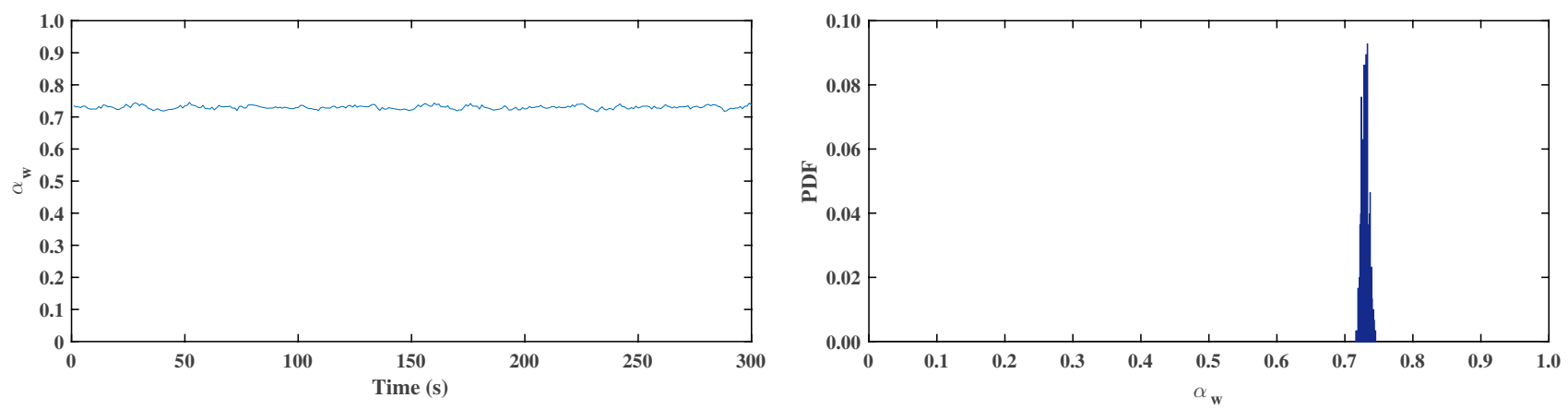

The vertical section

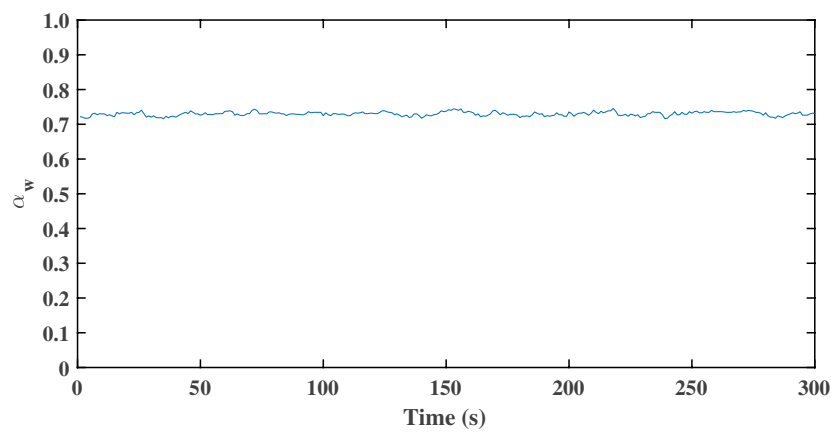

(a)

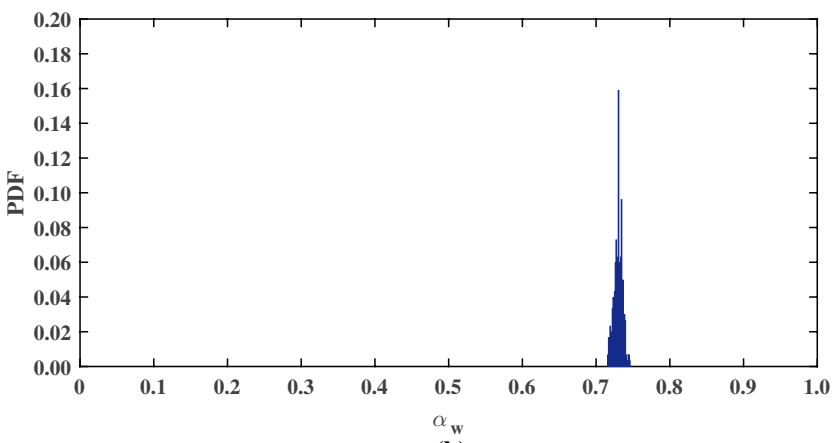

(b)

Figure 4. Typical evolution of the cross-sectional average water holdup $\alpha_{\mathrm{w}}$ and PDF for oil-water pipe flow: dispersion of oil in water $\left(u_{s \mathrm{w}}=0.16 \mathrm{~m} / \mathrm{s}, u_{s \mathrm{o}}=0.07 \mathrm{~m} / \mathrm{s}\right)$.

single narrow peak in both the horizontal and vertical sections, which indicates a small variance in water holdup. This is consistent with the characteristics of the dispersed flow and stratified flow ${ }^{2,13}$. Figure 4 shows the data for $u_{s \mathrm{~W}}=0.16 \mathrm{~m} / \mathrm{s}$ and $u_{s o}=0.07 \mathrm{~m} / \mathrm{s}$. O/W pattern was observed in the horizontal and vertical sections. The $\mathrm{O} / \mathrm{W}$ pattern was characterized by one narrow peak in the PDF at $\alpha_{\mathrm{w}}=0.72$ in this case. Figure 5 shows the result for $u_{s \mathrm{~W}}=0.02 \mathrm{~m} / \mathrm{s}$ and $u_{s \mathrm{o}}=0.20 \mathrm{~m} / \mathrm{s}$. W/O pattern was observed in the horizontal and vertical sections. The PDF showed a single narrow at a low input water holdup $\left(\alpha_{\mathrm{w}}<0.10\right)$. 
The horizontal section
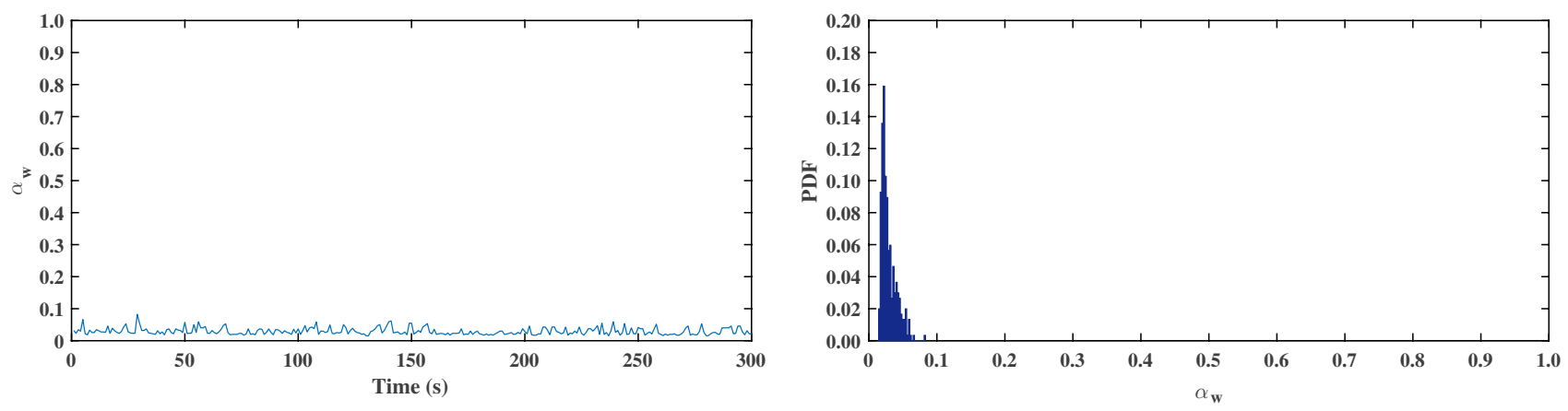

The vertical section

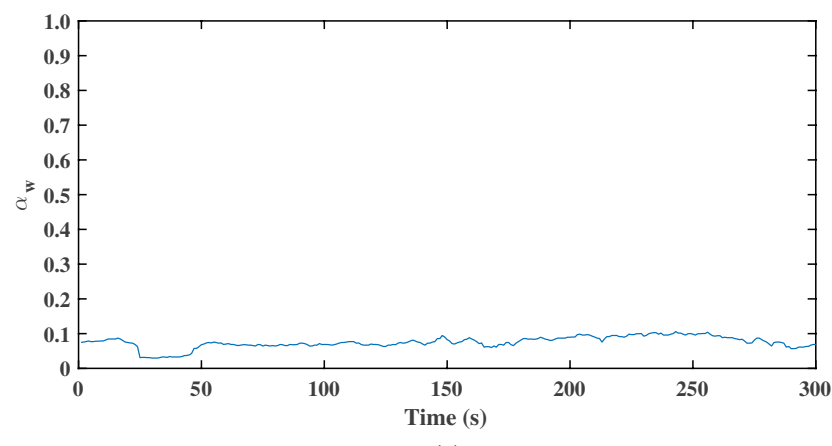

(a)

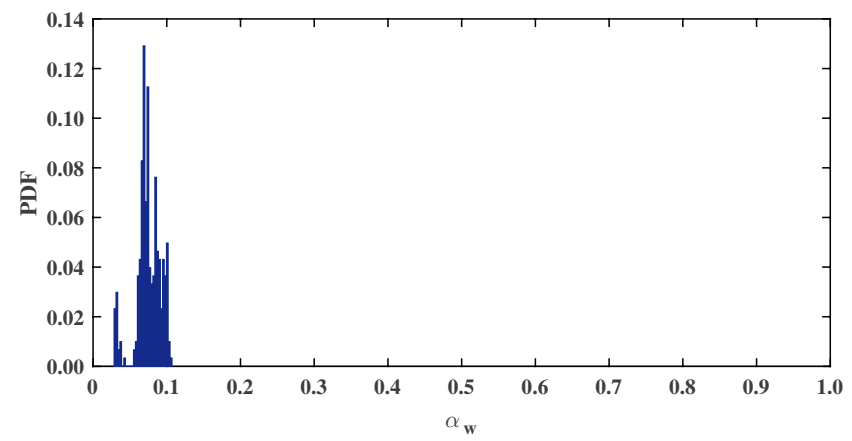

(b)

Figure 5. Typical evolution of the cross-sectional average water holdup $\alpha_{\mathrm{w}}$ and PDF for oil-water pipe flow: dispersion of water in oil $\left(u_{s \mathrm{w}}=0.02 \mathrm{~m} / \mathrm{s}, u_{s \mathrm{o}}=0.20 \mathrm{~m} / \mathrm{s}\right)$.

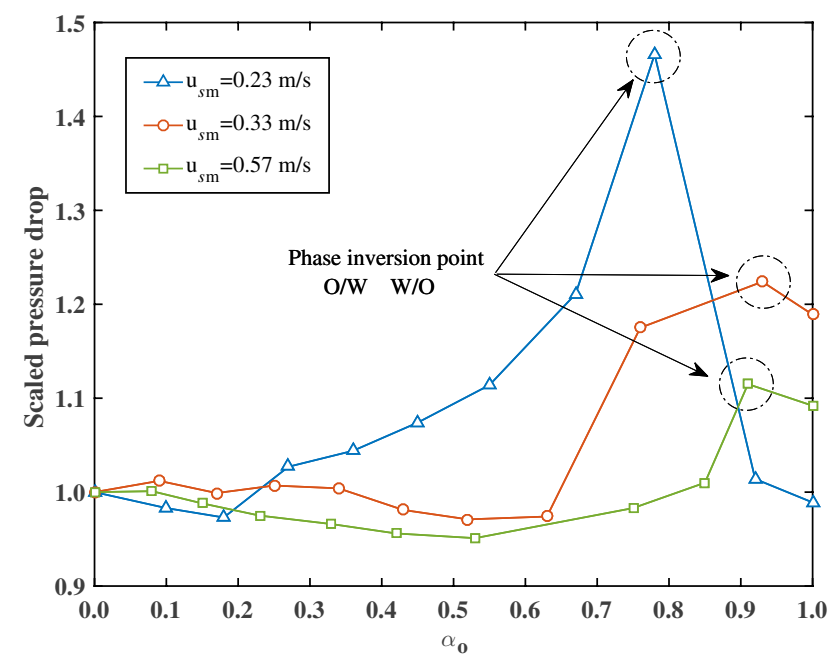

Figure 6. Scaled pressure drop as function of the oil holdup $\alpha_{\mathrm{o}}$ for three different total superficial velocities. The phase inversion occurs at an oil holdup between 0.75 and 0.95 .

The phase inversion point between $\mathrm{O} / \mathrm{W}$ and $\mathrm{W} / \mathrm{O}$ is usually defined as the critical holdup of the dispersed phase above which the dispersed phase becomes the continuous phase. Around the point of phase inversion, the effective mixture viscosity and the pressure drop fluctuate violently ${ }^{6,15}$. Figure 6 shows the scaled pressure drop (ratio of the measured pressure drop and the pressure drop of pure water) as a function of the oil holdup $\alpha_{\mathrm{o}}$ for three different total superficial velocities. The pressure drop increases slightly to a maximum value with increasing the oil holdup and then reduces immediately after passes through the maximum. In this study, phase inversion occurs at an oil holdup between 0.75 and 0.95. It can also be seen from Fig. 6 that the pressure drop decreases and the critical oil holdup at phase inversion increases with increasing total superficial velocities.

The flow pattern maps in terms of superficial velocities of oil and water studied in this paper are demonstrated in Fig. 7. Stratified flow (SF) is observed at high water velocities and low oil velocities in the horizontal section. 
(a) The horizontal section

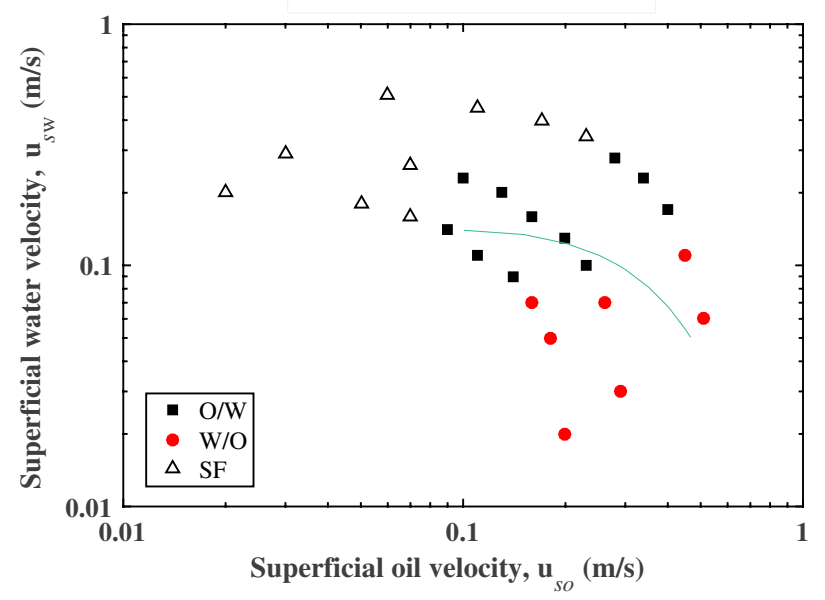

(b) The vertical section

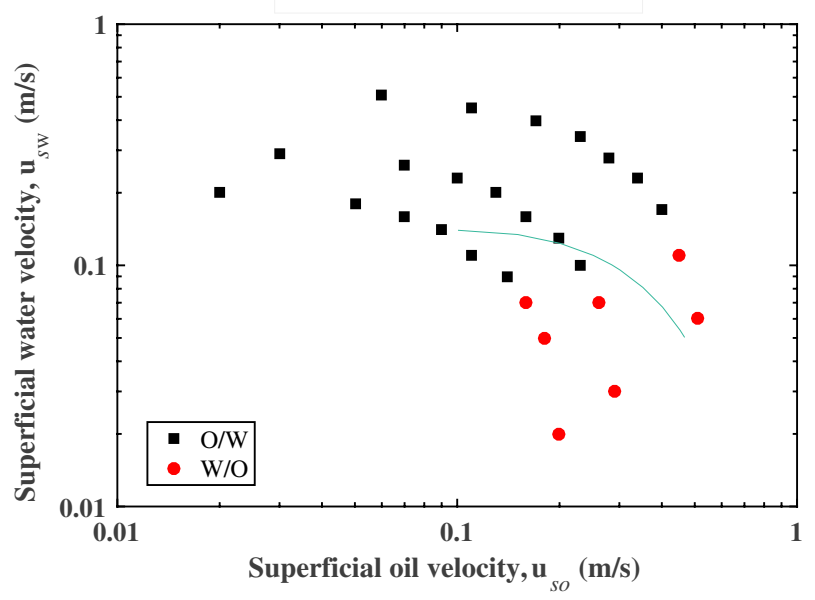

Figure 7. Flow pattern maps of oil-water two-phase pipe flow in (a) horizontal section and (b) vertical section. $\mu_{\mathrm{o}} / \mu_{\mathrm{w}}=32, \rho_{\mathrm{o}} / \rho_{\mathrm{w}}=0.84$.

For decreasing water velocities and increasing oil velocities, the transition to $\mathrm{O} / \mathrm{W}$ takes place. In the vertical section, only $\mathrm{O} / \mathrm{W}$ and $\mathrm{W} / \mathrm{O}$ flow patterns are observed. A comparison between Fig. 7a,b indicates there is a transition from horizontal stratified flow to vertical dispersed flow at the same superficial velocities. The region of $\mathrm{O} / \mathrm{W}$ flow is larger than that of W/O flow, and the transition boundary from $\mathrm{O} / \mathrm{W}$ and $\mathrm{W} / \mathrm{O}$ is almost identical in both the horizontal and vertical sections. The flow patterns in this experiment are obtained with $\mu_{\mathrm{o}} / \mu_{\mathrm{w}}=32$ and $\rho_{\mathrm{o}} / \rho_{\mathrm{w}}=0.84$.

Flow pattern transition mechanism. The boundary of the dispersed flow depends on the balance of the turbulent dispersive forces that tend to deform the drop and the surface tension that tend to resist fission. Brauner ${ }^{16}$ proposed a unified approach for predicting the transitions to dispersed flow patterns in gas-liquid and liquid-liquid systems. The transition criteria are based on the part of the work of Hinze ${ }^{17}$. In an oil-water system, the transition to $\mathrm{O} / \mathrm{W}$ takes place when the water turbulence is strong enough to decompose the oil into droplets smaller than the critical size $d_{\text {crit: }}$

$$
d_{\max } \leq d_{\text {crit }}
$$

where $d_{\max }$ is the maximum diameter that the droplet can reach under the combined action of shear force and surface tension. In dense dispersions, the maximum diameter is given by:

$$
\left(\frac{d_{\max }}{D}\right)=7.61 C_{\mathrm{H}}^{0.6}\left(\frac{\rho_{\mathrm{w}} u_{s \mathrm{~m}}^{2} D}{\sigma}\right)^{-0.6}\left(\frac{\rho_{\mathrm{w}} u_{s \mathrm{~m}} D}{\mu_{\mathrm{w}}}\right)^{0.08}\left(\frac{u_{s \mathrm{o}}}{u_{s \mathrm{w}}}\right)^{0.6}\left(1+\frac{\rho_{\mathrm{o}} u_{s \mathrm{o}}}{\rho_{\mathrm{w}} u_{s \mathrm{w}}}\right)^{-0.4}
$$

where $C_{\mathrm{H}}$ is a constant to be determined experimentally, $d_{\text {crit }}$ refers to the maximum diameter of the droplet without deformation, which can be expressed as:

$$
\frac{d_{\text {crit }}}{D}=\frac{0.224}{\left(\Delta \rho g D^{2} / 8 \sigma\right)^{0.5}}
$$

The scope of application of the above transition criterion is $\rho_{\mathrm{w}} \mathrm{u}_{s \mathrm{~m}} D / \mu_{\mathrm{w}} \geq 2100$ and $1.82\left(\rho_{\mathrm{w}} u_{\mathrm{sm}} D / \mu_{\mathrm{w}}\right)^{-0.7}<d_{\text {crit }} / D<0.1$.

The solid line in Fig. 7 represents the boundary that corresponds to the results of the criterion (10). In our experiments, it can better represent the trend from $\mathrm{O} / \mathrm{W}$ to $\mathrm{W} / \mathrm{O}$ when $C_{\mathrm{H}}=0.012$. The expression of the critical curve is:

$$
\left(u_{s \mathrm{o}}+u_{s \mathrm{w}}\right)^{1.12}\left(\frac{u_{s \mathrm{w}}}{u_{s \mathrm{o}}}\right)^{0.6}\left(1+\frac{\rho_{\mathrm{o}} u_{s \mathrm{o}}}{\rho_{\mathrm{w}} u_{s \mathrm{w}}}\right)^{0.4}=0.845 \frac{(\Delta \rho g)^{0.5} \sigma^{0.1} D^{0.48}}{\rho_{\mathrm{w}}^{0.52} \mu_{\mathrm{w}}^{0.08}}
$$

As can be seen in Fig. 7, Eq. (13) can provide somewhat reasonable predictions for phase inversion, although more experimental data are needed to improve the accuracy of the model prediction.

Phase holdup. The input water cut has an essential influence on the water holdup in the test section. Figures 8,9 and 10 shows the average water holdup of the time series in the horizontal and vertical sections at different total superficial velocities (corresponding to different $R e_{\mathrm{m}}$ and $F r_{\mathrm{m}}$ ). The dotted lines in Figs. 8, 9 and 10 represent the boundary between $\mathrm{W} / \mathrm{O}$ and $\mathrm{O} / \mathrm{W}$ flow patterns. In the range of $\mathrm{W} / \mathrm{O}$, oil forms the continuous phase $R e_{\mathrm{m}}=\rho_{\mathrm{o}} u_{s \mathrm{~m}} D / \mu_{\mathrm{o}}$, whereas, in the range of $\mathrm{O} / \mathrm{W}$, water forms the continuous phase $R e_{\mathrm{m}}=\rho_{\mathrm{w}} u_{s \mathrm{~m}} D / \mu_{\mathrm{w}}$. 


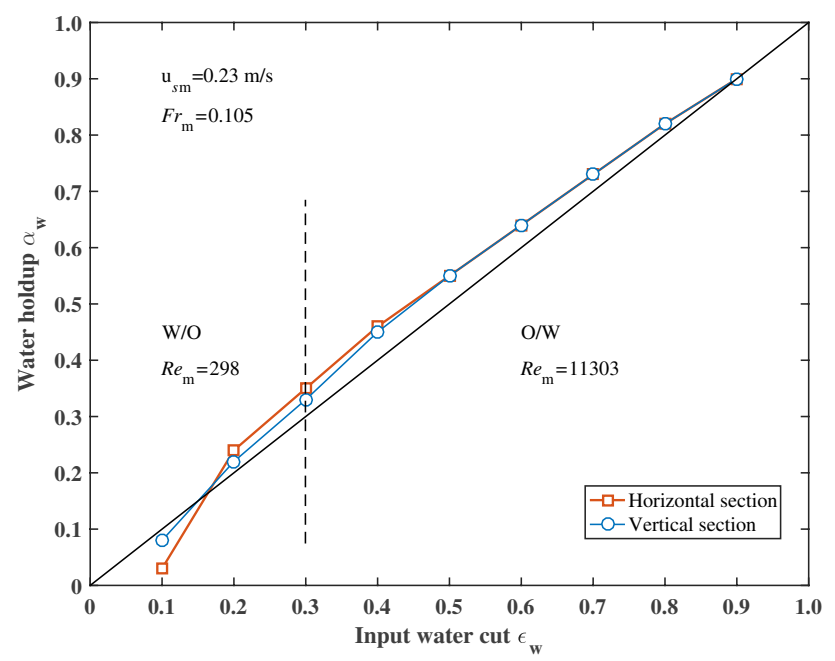

Figure 8. Average water holdup over input water cut at $u_{\mathrm{sm}}=0.23 \mathrm{~m} / \mathrm{s}$.

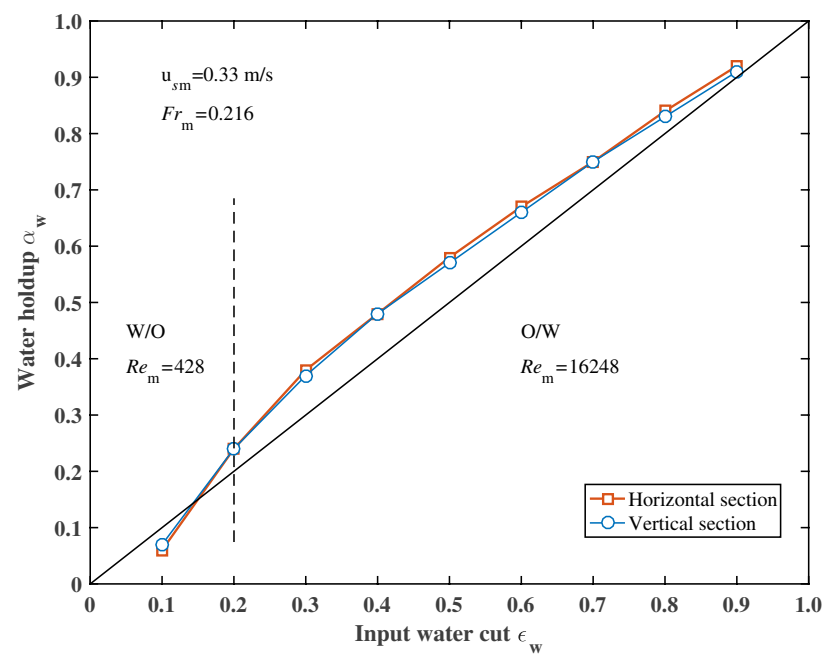

Figure 9. Average water holdup over input water cut at $u_{\mathrm{sm}}=0.33 \mathrm{~m} / \mathrm{s}$.

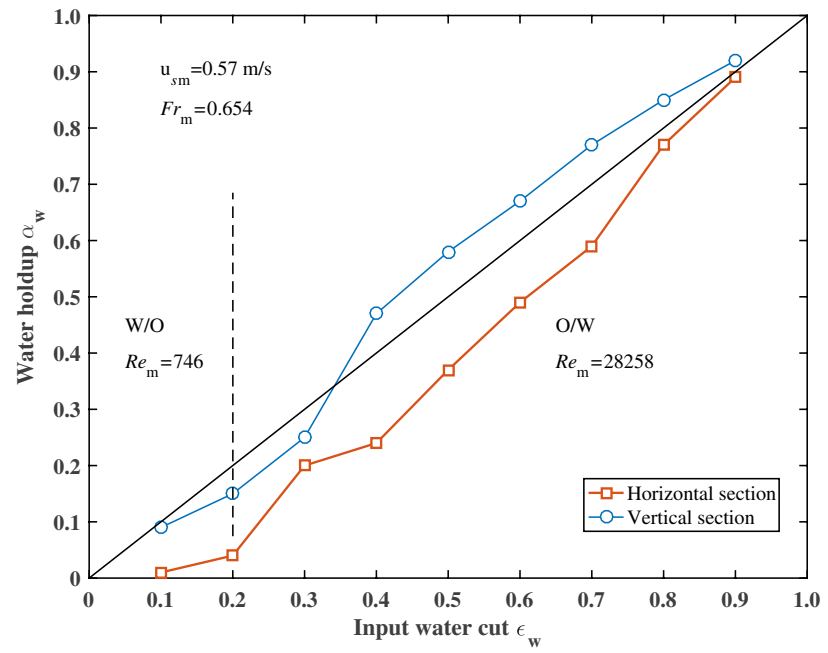

Figure 10. Average water holdup over input water cut at $u_{\mathrm{sm}}=0.57 \mathrm{~m} / \mathrm{s}$. 


\begin{tabular}{|l|l|l|l|l|}
\hline \multirow{2}{*}{ Parameter } & \multicolumn{3}{|l|}{ O/W flow pattern } & W/O flow pattern \\
\cline { 2 - 5 } & Horizontal section & Vertical section & Horizontal section & Vertical section \\
\hline$C$ & 0.65 & 32.4 & - & 10.3 \\
\hline$n$ & 0.17 & 1.17 & - & 1.80 \\
\hline Standard deviation (SD) & $4.22 \%$ & $4.40 \%$ & - & $6.49 \%$ \\
\hline
\end{tabular}

Table 3. The values of $C$ and $n$ for experimental data predicted by using the drift-flux model.

For $F r_{\mathrm{m}}=0.105$ and 0.216 , there are no significant differences in water holdup between horizontal and vertical sections (Figs. 8 and 9). At lower input water cut corresponding to experimental data, the water holdup is slightly lower than the input water cut, i.e., there is a significant velocity difference between the oil and water phases. The range with a smaller water holdup corresponds to the W/O flow pattern range. In the range of the $\mathrm{O} / \mathrm{W}$ flow pattern, the water holdup is larger than the input water cut. The transition point appears at an input water cut of about 0.2 . For $F r_{\mathrm{m}}=0.654$, the transition point of water holdup from less than input water cut to higher than the input water cut appears at an input water cut of about 0.35 in the vertical section. However, the water holdup is considerably lower than the input water cut in the horizontal section due to water flows faster at this condition (Fig. 10). It also can be seen that for dispersed $\mathrm{O} / \mathrm{W}$ flow with high input water cut $\left(\varepsilon_{\mathrm{w}}=0.9\right)$ the dispersed oil droplets travel at approximately the same velocity as the water. The velocity difference between oil and water is close to zero. The result is also similar to that in gas-liquid flow ${ }^{2}$.

The concentration variation of the dispersed phase in the pipe can be predicted by the drift-flux model proposed by Zuber and Findlay ${ }^{18}$. Hasan and Kablr ${ }^{10}$ successfully applied the drift-flux model to the oil-water two-phase flow to predict the concentration of the dispersed phase. For the O/W flow pattern, the drift-flux model calculates the oil holdup:

$$
\frac{u_{s o}}{\alpha_{\mathrm{o}}}=C u_{s \mathrm{~m}}+\frac{J_{d}}{\alpha_{o}}
$$

where $J_{d}$ is the drift flux that can be calculated by the following semi-theoretical relationship:

$$
J_{d}=u_{\infty} \alpha_{\mathrm{o}}\left(1-\alpha_{\mathrm{o}}\right)^{n}
$$

where $C$ and $n$ are parameters determined by experiments, $u_{\infty}$ is the terminal rise velocity of an oil droplet in the static water column, which is calculated by the Harmathy correlation ${ }^{19}$.

$$
u_{\infty}=1.53\left[\sigma\left(\rho_{\mathrm{w}}-\rho_{\mathrm{o}}\right) g / \rho_{\mathrm{w}}^{2}\right]^{0.25}
$$

Substituting Eq. (15) into Eq. (14) yields the following correlation:

$$
u_{s o} / \alpha_{\mathrm{o}}=C u_{s \mathrm{~m}}+u_{\infty}\left(1-\alpha_{\mathrm{o}}\right)^{n}
$$

Similarly, for the W/O flow pattern, the drift-flux model is transformed into the following form:

$$
u_{s \mathrm{w}} / \alpha_{\mathrm{w}}=C u_{s \mathrm{~m}}+u_{\infty l}\left(1-\alpha_{\mathrm{w}}\right)^{n}
$$

where $u_{\infty l}$ is the terminal settlement velocity of a water droplet in static oil column which is calculated by:

$$
u_{\infty l}=1.53\left[\sigma\left(\rho_{\mathrm{w}}-\rho_{\mathrm{o}}\right) g / \rho_{\mathrm{o}}^{2}\right]^{0.25}
$$

The values of $C$ and $n$ can be obtained by curve fitting analysis of experimental data. The fitting results for the horizontal and vertical sections are presented in Table 3. The standard deviation (SD) of the predicted value can be expressed as $^{20}$ :

$$
\mathrm{SD}=\sqrt{\frac{1}{n-1} \sum_{k=1}^{n}\left(\frac{\left(\alpha_{D}\right)_{\text {pred }}-\left(\alpha_{D}\right)_{\exp }}{\left(\alpha_{D}\right)_{\exp }}\right)^{2}}
$$

Figure 11 depicts a comparison of the predicted dispersed phase holdup with the experimental data. The square and circular symbols represent the data of the horizontal section and the vertical section, respectively. Better fitting results are obtained for the $\mathrm{O} / \mathrm{W}$ flow pattern, and the standard deviation of fitting data is within $4.5 \%$. In the range of the $\mathrm{W} / \mathrm{O}$ flow pattern, a good agreement is obtained for the experimental data of the vertical section at a standard deviation of $6.49 \%$. However, the data in the horizontal section cannot be predicted by the drift-flux model. The reason may be due to the measured holdup data for the horizontal section in the low input water cut are considered to be less reliable. Overall, the existing model provides good estimates of the oil holdup in the dispersion of oil in water flow. 
(a) Dispersion of oil in water

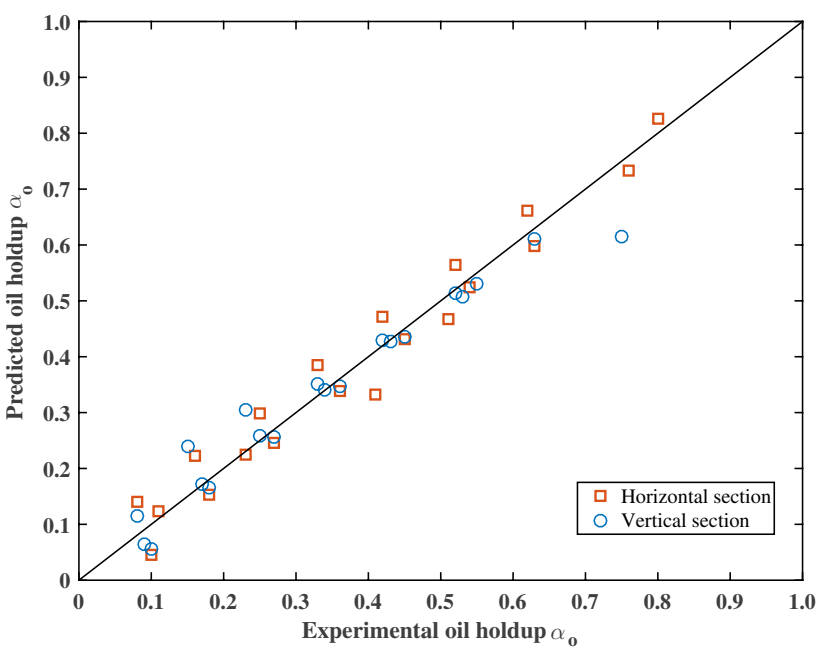

(b) Dispersion of water in oil

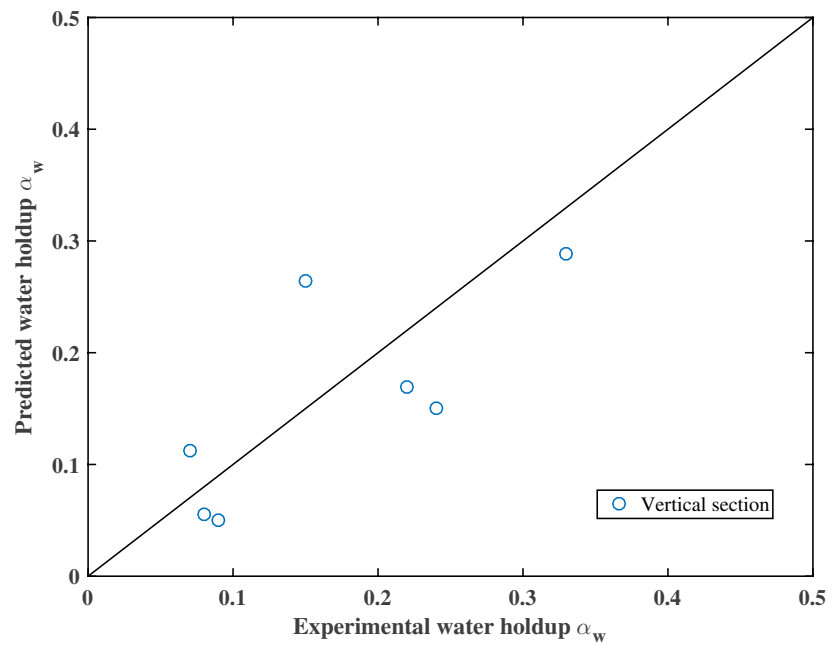

Figure 11. Comparison between the predicted dispersed phase holdup with the experimental data for (a) dispersion of oil in water flow pattern and (b) dispersion of water in oil flow pattern.

\section{Conclusion}

The oil-water two-phase flow experiments have been conducted in the horizontal and vertical sections of the pipe simultaneously. The difference of oil-water two-phase distribution in horizontal and vertical sections is investigated and discussed. The newly designed water holdup instrument equipped with a conductance probe is used to measure the cross-sectional average water holdup.

The dispersed flow (W/O and $\mathrm{O} / \mathrm{W}$ ) and stratified flow have been identified over the range of oil and water superficial velocities. The pressure drop reaches the maximum value at the phase transition point of $\mathrm{O} / \mathrm{W}$ and $\mathrm{W} / \mathrm{O}$ in this study. The phase transition occurs at the oil holdup between 0.75 and 0.95 . Based on the model of Brauner ${ }^{16}$, a unified correlation for predicting the transition between $\mathrm{O} / \mathrm{W}$ and $\mathrm{W} / \mathrm{O}$ is suggested. The model can provide a reasonable prediction for phase inversion. The drift-flux model proposed by Zuber and Findlay ${ }^{18}$ is modified for predicting the concentration of the dispersed phase in the horizontal and vertical sections. The model can well predict the concentration distribution of the O/W flow patterns. For the W/O flow pattern, the model is suitable for predicting the concentration change in the vertical section but fails to predict the concentration change in the horizontal section.

Received: 19 August 2021; Accepted: 28 September 2021

Published online: 11 October 2021

\section{References}

1. Ghorai, S., Suri, V. \& Nigam, K. D. P. Numerical modeling of three-phase stratified flow in pipes. Chem. Eng. Sci. 60, 6637-6648. https://doi.org/10.1016/j.ces.2005.05.050 (2005).

2. Ibarra, R., Nossen, J. \& Tutkun, M. Two-phase gas-liquid flow in concentric and fully eccentric annuli. Part I: Flow patterns, holdup, slip ratio and pressure gradient. Chem. Eng. Sci. 203, 489-500. https://doi.org/10.1016/j.ces.2019.01.064 (2019).

3. Ren, G. et al. The flow pattern transition and water holdup of gas-liquid flow in the horizontal and vertical sections of a continuous transportation pipe. Water 13, 2077. https://doi.org/10.3390/w13152077 (2021).

4. Flores, J. G. Characterization of oil-water flow patterns in vertical and deviated wells. Soc. Petrol. Eng. $\mathbf{3 8 8 1 0}$ (1997).

5. Piela, K. et al. Experimental investigation of phase inversion in an oil-water flow through a horizontal pipe loop. Int. J. Multiph. Flow 32, 1087-1099. https://doi.org/10.1016/j.ijmultiphaseflow.2006.05.001 (2006).

6. Gong, J., Li, Q. P., Yao, H. Y. \& Yu, D. A model for predicting phase inversion in oil-water two-phase pipe flow. J. Hydrodyn. 18, 310-314 (2006).

7. Kumara, W. A. S., Elseth, G., Halvorsen, B. M. \& Melaaen, M. C. Comparison of particle image velocimetry and laser doppler anemometry measurement methods applied to the oil-water flow in horizontal pipe. Flow Meas. Instrum. 21, 105-117. https:// doi.org/10.1016/j.flowmeasinst.2010.01.005 (2010).

8. Zhou, Y. Y., Jin, N. D., Zhang, H. X. \& Zhai, L. S. Method based on parallel-wire conductivity probe for measuring water hold-up in nearhorizontal oil-water two-phase flow pipes. IET Sci. Meas. Technol. 14, 676-683. https://doi.org/10.1049/iet-smt.2019.0308 (2020).

9. Wang, C. L., Tian, M. C., Zhang, J. Z. \& Zhang, G. M. Experimental study on liquid-liquid two-phase flow patterns and plug hydrodynamics in a small channel. Exp. Thermal Fluid Sci. 129, 110455. https://doi.org/10.1016/j.expthermflusci.2021.110455 (2021).

10. Hasan, A. R. \& Kablr, C. S. A new model for two-phase oil/water flow: production log interpretation and tubular calculations. Soc. Petrol. Eng. SPE 5, 193-199 (1990).

11. Xu, J. Y., Li, D. H., Guo, J. \& Wu, Y. X. Investigations of phase inversion and frictional pressure gradients in upward and downward oil-water flow in vertical pipes. Int. J. Multiph. Flow 36, 930-939. https://doi.org/10.1016/j.ijmultiphaseflow.2010.08.007 (2010).

12. Keska, J. K., Smith, M. D. \& Williams, B. E. Comparison study of a cluster of four dynamic flow pattern discrimination techniques for multiphase flow. Flow Meas. Instrum. 10, 65-77 (1999).

13. Jones, O. C. \& Zuber, N. The interrelation between void fraction fluctuations and flow patterns in two-phase flow. Int. J. Multiph. Flow 2, 273-306 (1975). 
14. Du, M., Yin, H. G., Chen, X. Y. \& Wang, X. Q. Oil-in-water two-phase flow pattern identification from experimental snapshots using convolutional neural network. IEEE Access 7, 6219-6225. https://doi.org/10.1109/access.2018.2888733 (2019).

15. Descamps, M. N., Oliemans, R. V. A., Ooms, G. \& Mudde, R. F. Experimental investigation of three-phase flow in a vertical pipe: Local characteristics of the gas phase for gas-lift conditions. Int. J. Multiph. Flow 33, 1205-1221. https://doi.org/10.1016/j.ijmul tiphaseflow.2007.06.001 (2007).

16. Brauner, N. The prediction of dispersed flows boundaries in liquid-liquid and gas-liquid systems. Int. J. Multiphase Flow (2001).

17. Hinze, J. O. Fundamentals of the hydrodynamic mechanism of splitting in dispersion processes. AIChE J. 1, 289-295. https://doi. org/10.1002/aic.690010303 (1955).

18. Zuber, N. \& Findlay, J. A. Average volumetric concentration in 2-phase flow systems. J. Heat Transf. 87, 453. https://doi.org/10. $1115 / 1.3689137$ (1965).

19. Harmathy, T. Z. Velocity of lager drops and bubbles in media of infinite or restricted extent. AIChE J. 6, 281-288. https://doi.org/ 10.1002/aic.690060222 (1960).

20. Al-Wahaibi, T. Pressure gradient correlation for oil-water separated flow in horizontal pipes. Exp. Thermal Fluid Sci. 42, 196-203. https://doi.org/10.1016/j.expthermflusci.2012.04.021 (2012).

\section{Author contributions}

All the authors have contributed equally to this manuscript.

\section{Competing interests}

The authors declare no competing interests.

\section{Additional information}

Correspondence and requests for materials should be addressed to P.L.

Reprints and permissions information is available at www.nature.com/reprints.

Publisher's note Springer Nature remains neutral with regard to jurisdictional claims in published maps and institutional affiliations.

(1) Open Access This article is licensed under a Creative Commons Attribution 4.0 International License, which permits use, sharing, adaptation, distribution and reproduction in any medium or format, as long as you give appropriate credit to the original author(s) and the source, provide a link to the Creative Commons licence, and indicate if changes were made. The images or other third party material in this article are included in the article's Creative Commons licence, unless indicated otherwise in a credit line to the material. If material is not included in the article's Creative Commons licence and your intended use is not permitted by statutory regulation or exceeds the permitted use, you will need to obtain permission directly from the copyright holder. To view a copy of this licence, visit http://creativecommons.org/licenses/by/4.0/.

(C) The Author(s) 2021 